\author{
Mr Vladimir Š́epec
}

\section{MODELOVANJE I ANALIZA PROTIVOKLOPNE BORBE}

UDC: $355.424 .5: 358.116$

Rezime:

$U$ radu je prikazan jedan pristup modeliranja $i$ analize protivoklopne borbe. Primenjena je teorija masovnog opsluživanja, linearne transcedentalne jednačine $i$ teorija verovatnoće u analizi parametara za procenu efikasnosti protivoklopne borbe.

Ključne reči: teorija masovnog opsluživanja, efikasnost, protivoklopna borba.

\title{
MODEL AND ANALYSIS ANTITANK COMBAT
}

Summary:

An approach in antitank combat modeling and analysis has been presented. The theory of mass servicing, linear transcendental equations and the theory of probability have been used in analyzing the parameters of antitank combat efficiency estimation.

Key words: mass servicing theory, efficiency, antitank combat.

\section{Uvod}

Prema ukupnom doprinosu i uticaju na tok i rezultate oružane borbe, protivoklopna borba (POB) ima strategijski značaj.

Njome se slama napadna moć, slabi silina udara, smanjuje tempo napada, uništavaju i razbijaju oklopno-mehanizovane snage protivnika i time sprečavaju brzi i duboki prodori njegovih kopnenih snaga.

Respektabilnost POB potvrđuju i osobine savremenih tenkova: velika vatrena moć, velika pokretljivost, automatsko punjenje topa i različite vrste projektila, daljinsko upravljanje protivavionskim mitraljezom, aktivno-reaktivni oklop, optoelektronski uređaji za dnevno-noćno kretanje i gađanje, laserski daljinomeri, lasersko vođenje protivoklopnih raketa, optičko-elektronski uređaji za neutralisanje protivničkih vođenih raketa, bacači dimnih kutija, radio-uređaji sa frekvencijskim skakanjem, i drugo.

\section{Analitički model za procenu efikasnosti protivoklopne borbe}

Kao kriterijumi ocene borbene efikasnosti raketnih sistema POB (kao i protivoklopne artiljerije) može se primenjivati matematičko očekivanje broja uništenih tenkova (oklopnih transportera) u toku odbijanja napada [1]: ${ }^{1}$

$N_{u}=N \cdot\left[1-\left(1-e^{-\frac{n_{u}}{n}} \cdot p_{m} \cdot p_{u}\right)^{\frac{n}{N}}\right]$ 
gde je:

$\mathrm{N}_{\mathrm{u}}$ - srednji broj uništenih ciljeva (tenkova i transportera),

$\mathrm{N}$ - ukupan broj ciljeva (tenkova i transportera) koji učestvuju u napadu na branjenu teritoriju,

$\mathrm{n}$ - broj lansera raketa ili PT topova na branjenoj teritoriji,

$\mathrm{n}_{\mathrm{u}}-$ broj uništenih lansera ili PT topova,

$\mathrm{p}_{\mathrm{m}}$ - verovatnoća pogađanja cilja $\mathrm{i}$

$\mathrm{p}_{\mathrm{u}}$ - verovatnoća uništenja (gađanja) cilja, tj. verovatnoća da će se po cilju dejstvovati.

Veličinu $\mathrm{p}_{\mathrm{m}}$ moguće je odrediti na osnovu formule:

$p_{m}=1-\left(1-p_{1}\right)^{m}$

gde je:

$\mathrm{p}_{1}$ - verovatnoća pogađanja cilja jednom protivtenkovskom raketom ili jednim projektilom PT topa i

$\mathrm{m}$ - broj raketa.

Za određivanje verovatnoće $p_{u}$ neophodno je poznavati vreme koje je potrebno za lansiranje jedne rakete (sa vođenjem, ako nije samonavođena), odnosno projektila kod PT oruđa, a zvaće se vreme opsluživanja $\left(t_{o p}\right)$ i dužinu vremena, kada se cilj nalazi u zoni gađanja, a koja će se zvati vreme gađanja $\left(\mathrm{t}_{\mathrm{g}}\right)$.

Analizom svakog pojedinačnog lansera (ili PT topa) kao jednokanalnog sistema opsluživanja sa otkazom, ${ }^{2}$ dobija se verovatnoća uništenja [1]:

$$
p_{u}=1-\frac{\frac{\rho}{p_{i}}}{1+\frac{\rho}{p_{i}}}
$$

\footnotetext{
${ }^{2}$ Pri analizi polazimo od pretpostavke da se pojavljiva-
} nje ciljeva može identifikovati kao Poasonov tok. gde je:

$\mathrm{p}_{\mathrm{i}}$ - verovatnoća otkrivanja cilja, koja se procenjuje na osnovu empirijskih rezultata $\mathrm{i}$

$\rho$ - parametar koji se proračunava na osnovu izraza:

$\rho=\frac{t_{o p}}{t_{g}}$

gde je:

$\mathrm{t}_{\mathrm{op}}$ - srednje vreme opsluživanja,

$\mathrm{t}_{\mathrm{g}}$ - vreme gađanja cilja.

Srednje vreme opsluživanja može se izračunati kao:

$t_{o p}=\frac{T_{n}}{q}$

gde je:

$\mathrm{T}_{\mathrm{n}}$ - prognozirano vreme kretanja cilja, $\mathrm{q}$ - količina PO raketa ili projektila, koji se za to vreme mogu lansirati (ova analiza odnosiće se na broj lansiranja / gađanja u minuti).

Vreme gađanja cilja može se predstaviti izrazom:

$t_{g}=\frac{D_{d}-D_{b}}{V_{c}}$

gde je:

$\mathrm{D}_{\mathrm{d}}, \mathrm{D}_{\mathrm{b}}$ - dalja i bliža granica zone mogućeg dejstva, $\mathrm{V}_{\mathrm{c}}$ - srednja brzina kretanja cilja.

Pošto se ova analiza odnosi na borbu na tzv. srednjim daljinama, ${ }^{3}$ pitanje je da li verovatnoću otkrivanja cilja $\mathrm{p}_{2}$ treba razmatrati.

POB se uslovno po daljini može podeliti na: blisku borbu do $1000 \mathrm{~m}$, borbu na srednjem odstojanju 1000-3000 m i velikom odstojanju preko $3000 \mathrm{~m}$ [2] 
Sigurno je da bez obzira na relativno malu daljinu (malo odstojanje) verovatnoća otkrivanja cilja neće uvek biti jedan $\left(\mathrm{p}_{\mathrm{i}} \leq 1\right),{ }^{4}$ a to se posebno odnosi na dejstva u uslovima slabe vidljivosti ili kada se koriste dimne i aerosolne ,zave-

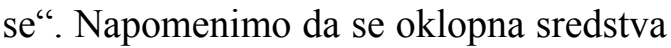
na ovim daljinama - odstojanjima mogu otkriti vizuelno ili uz pomoć radara za otkrivanje borbenih ili optoelektronskih sredstava (pojačavača svetlosti, televizije i televizije niskog nivoa osvetljenosti, termovizije i drugo). Naravno, ostaje još jedno sredstvo, a to je radio-izviđanje, kada oklopne jedinice „moraju“ da koriste radio-veze. Međutim, zadatak radio-izviđanja najčešće će biti otkrivanje radio-veze radi njenog ometanja. ${ }^{5}$

\section{Ilustrativni primer}

Razmotrimo jedan proizvoljan primer. Na ravničarskom zemljištu, na delu fronta, napada tenkovska jedinica sastava 10 tenkova. $^{6}$ Nalazi se na odstojanju od oko $3 \mathrm{~km}$ od prednjeg kraja odbrane, gde je razmešteno 5 lansera za POB. Tenkovi se kreću brzinom od oko $50 \mathrm{~km} / \mathrm{h}$, što znači da će oko 2 minuta (za koje će preći oko 1500-2000 m) biti u dometu za gađanje. Poznato je da je za lansiranje jedne PO rakete potrebno oko $30^{\prime \prime}\left(15^{\prime \prime}\right)$. Verovatnoća pogađanja raketa je $0,8\left(\mathrm{p}_{\mathrm{m}}\right.$ $=0,8)$, kao i verovatnoća otkrivanja tenkova $\left(\mathrm{p}_{\mathrm{i}}=0,8\right)$. Ako je za dejstvo potrebno $30^{\prime \prime}\left(t_{o p}=0,5\right)$, a cilj je u zoni dejstva $2^{\prime}\left(\mathrm{t}_{\mathrm{g}}=2\right)$, tada je $\rho=0,25$, pa verovatno-

\footnotetext{
${ }^{4}$ Može se procenjivati na osnovu statističkih podataka sa taktičkih vežbi.

${ }^{5}$ Verovatnoća radio-izviđanja i ometanja može da se izračuna pomoću formule Erlanga [1].

${ }^{6}$ Borbene mogućnosti savremenih tenkova su poznate $i$ zato se neće posebno navoditi.
}

ća uništenja/gađanja - prema izrazu (3) iznosi:

$$
p_{u}=1-\frac{\frac{0,25}{0,8}}{1+\frac{0,25}{0,8}}=0,76
$$

Kada se unesu sve poznate veličine u izraz (1), uz ograničenje da je parame$\operatorname{tar} n_{u}=0$ (trenutno nema uništenih PO lansera), dobija se:

$$
N_{u}=10 \cdot\left[1-\left(1-e^{-\frac{0}{5}} \cdot 0,8 \cdot 0,76\right)^{\frac{5}{10}}\right]
$$

pa je $\mathrm{N}_{\mathrm{u}}=3,7 \approx 4$ za iste uslove, ali ako nam je $t_{\text {op }}=0,25\left(15^{\prime \prime}\right)$, tada je $\rho=0,125$, a $p_{u}=0,87$, pa je $N_{u}=4,6 \approx 5$.

Rezultate treba uporediti sa statističkim podacima sa bojnih gađanja i taktičkih vežbi i na taj način oceniti validnost ponuđenog matematičkog modela.

\section{Analiza parametara koji utiču na efikasnost protivoklopne borbe}

Mogu se, takođe, analizirati različite moguće varijante sa različitim brojem lansera, brojem uništenih lansera (kao protivdejstva), različitom verovatnoćom otkrivanja, pogađanja i uništenja cilja, skraćivanjem vremena lansiranja i drugo. Primeri kvantitativne analize ilustrovani su na narednim grafikonima. Predstavljene su zavisnosti srednjeg broja uništenih ciljeva i verovatnoće uništenja cilja u zavisnosti od parametara predstavljenih u matematičkim 


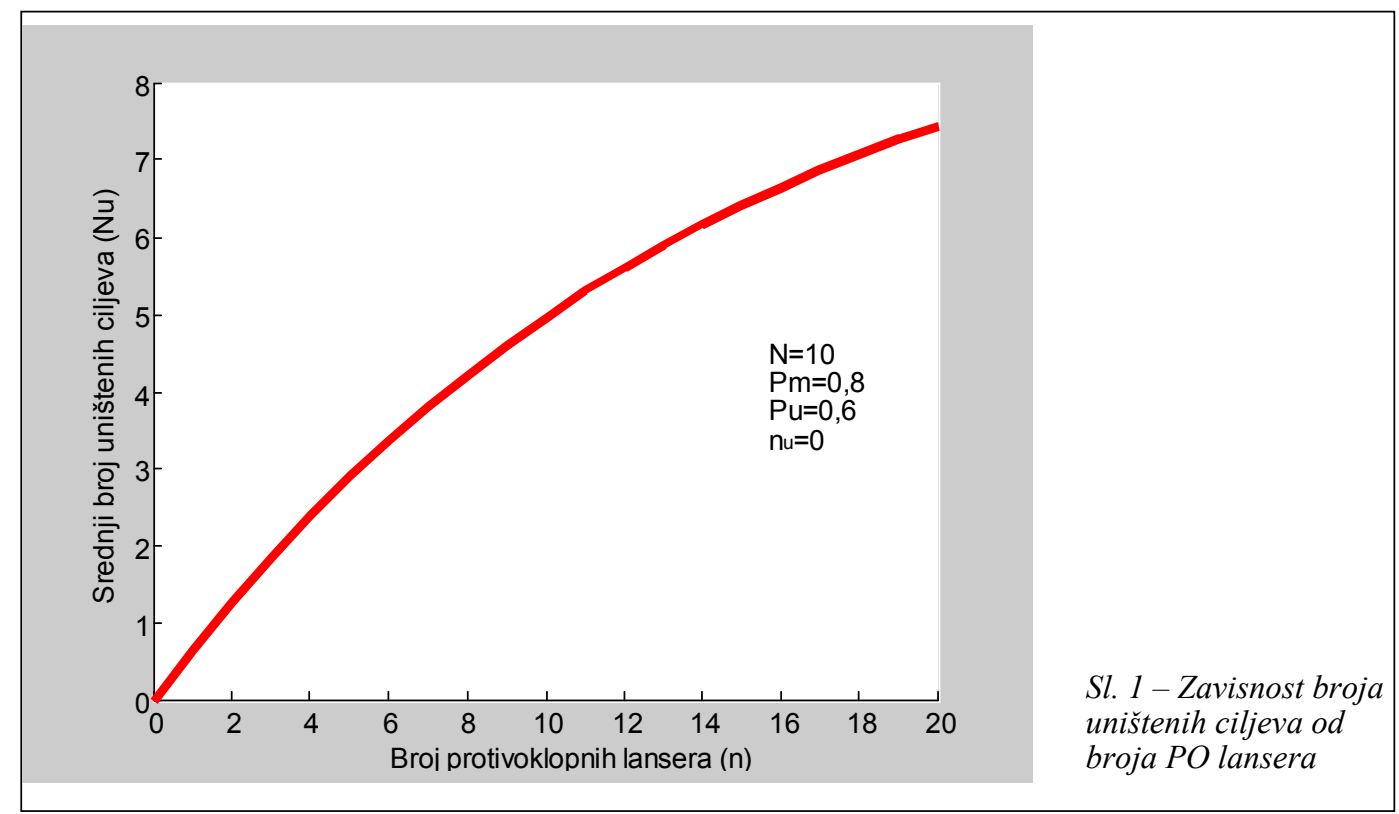

izrazima. Za prezentovane krive zavisnosti urađeni su programi u programskom paketu Matlabu 6.5R13, koji omogućavaju lakšu i bržu analizu i proračune neophodne za procenu efikasnosti protivoklopne borbe.

Zavisnost srednjeg broja uništenih ciljeva od broja lansera (PT topova), za poznate verovatnoće uništenja, pogađanja i otkrivanja ciljeva $\left(\mathrm{p}_{\mathrm{i}}=0,8\right)$ i poznatom parametru $\rho=0,5$, predstavljena je na slici 1. Ova međuzavisnost omogućava da se izabere što celishodniji odnos broja lansera prema broju tenkova u borbi za određene uslove.

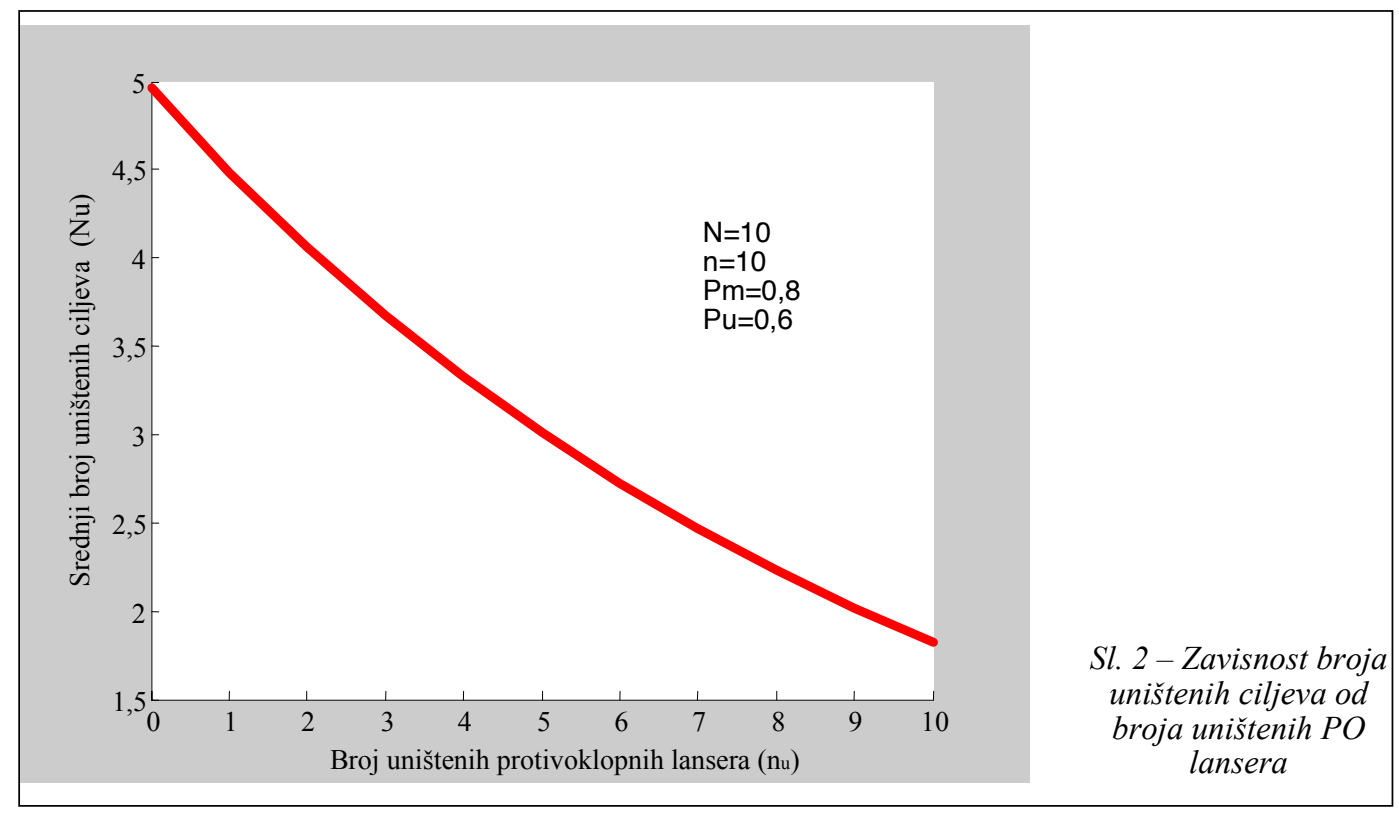


$\mathrm{Na}$ slici 2 prikazana je zavisnost broja uništenih ciljeva od broja uništenih lansera (PT topova). Sigurno je da se u borbenim dejstvima mora računati i na gubitke. Analiza ukazuje na značaj protivoklopnog obezbeđenja, gde spadaju: iz- viđanje i javljanje, protivoklopno zaprečavanje, fortifikacijsko uređenje zemljišta i druge mere koje sprovode jedinice [2]. Kriva zavisnosti pokazuje da se sa gubitkom polovine sredstava smanjuje i broj uništenih ciljeva skoro za polovinu.

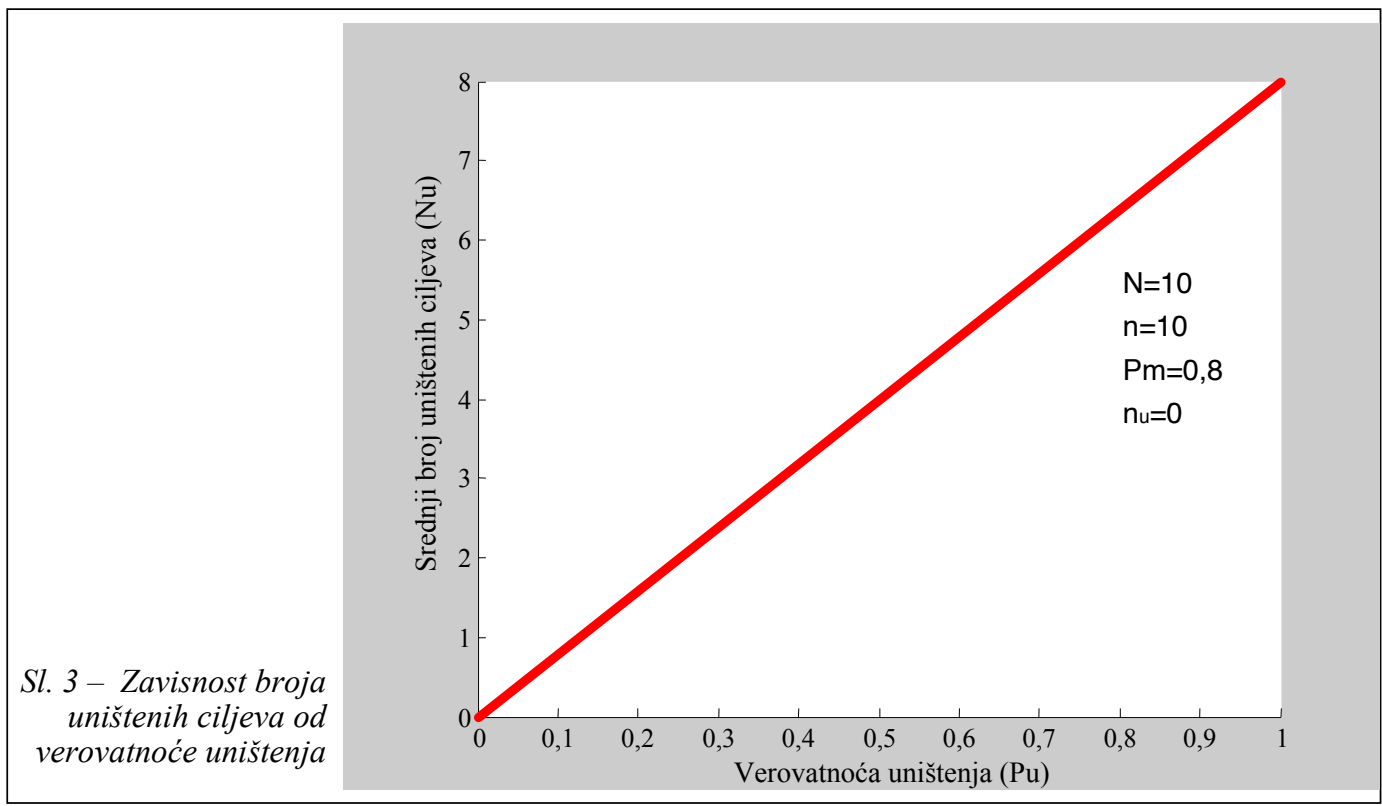

Zavisnost srednjeg broja uništenih ciljeva od verovatnoće uništenja, odnosno verovatnoće da će po cilju biti izvršena dejstva (lansirane PT rakete ili projektili), kada je verovatnoća otkrivanja ciljeva $\left(\mathrm{p}_{\mathrm{i}}=1\right)$ i parametar $\rho \leq 1$, vidi se na slici 3 . Treba težiti da verovatnoća uništenja bude što veća, tj. približno 1. Da bi se to postiglo, potrebno je da verovatnoća izviđanja bude, takođe, što veća, a parametar $\rho$ što manji.

Uticaj parametra $\rho$ na verovatnoću uništenja cilja, koji predstavlja odnos srednjeg vremena opsluživanja i raspoloživog vremena za gađanje cilja, u za- visnosti od verovatnoće izviđanja, predstavljen je krivama zavisnosti na slici 4.

$\mathrm{Na}$ osnovu predstavljenih krivih zavisnosti na slici 4 očigledno je da je potrebno imati što kraće vreme za opsluživanje i što duže vreme za gađanje cilja, pošto se u tim uslovima postiže najveća verovatnoća uništenja cilja. To se može obezbediti pravilnim izborom sredstava i položaja za dejstvo. Zato je najcelishodnije koristiti lansirna sredstva na oklopnim transporterima i helikopterima, ukoliko se njima raspolaže, što ilustruju i dobijene veličine prikazane u tabeli. 


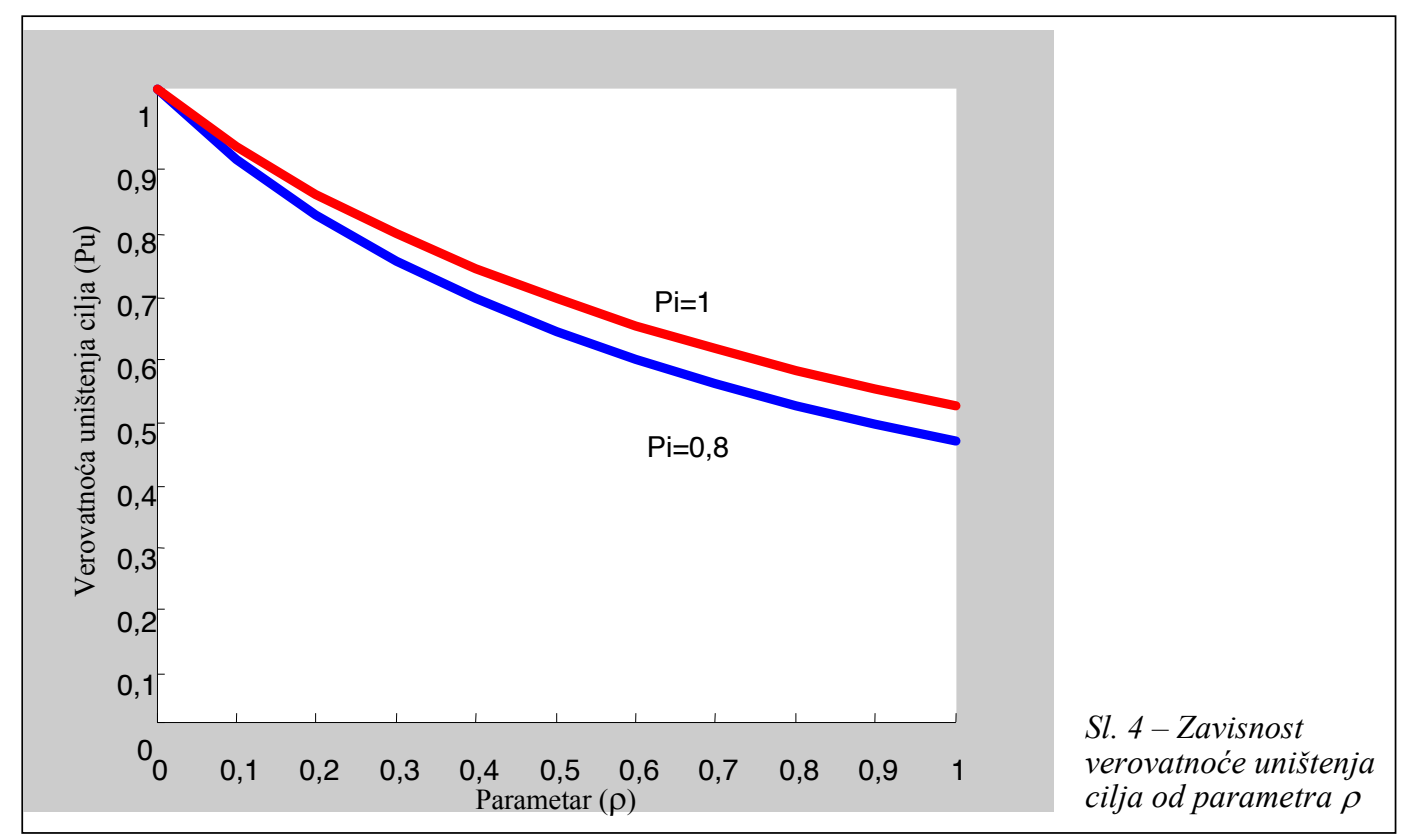

\begin{tabular}{|c|c|c|c|c|c|}
\hline $\mathrm{t}_{\mathrm{op}}$ & $\mathrm{t}_{\mathrm{g}}$ & $\rho$ & $p_{\mathrm{i}}$ & $p_{\mathrm{u}}$ & $\begin{array}{c}\text { Broj lansiranih } \\
\text { raketa (projektila) }\end{array}$ \\
\hline $1^{\prime}$ & $1^{\prime}$ & 1 & 1 & 0,5 & 1 \\
\hline $30^{\prime \prime}$ & $1^{\prime}$ & 0,5 & 1 & 0,66 & 2 \\
\hline $1^{\prime \prime}$ & $1^{\prime}$ & 0,25 & 1 & 0,8 & 4 \\
\hline $7,5^{\prime \prime}$ & $1^{\prime}$ & 0,125 & 1 & 0,88 & 8 \\
\hline $1^{\prime}$ & $2^{\prime}$ & 0,5 & 1 & 0,66 & 2 \\
\hline $30^{\prime \prime}$ & $2^{\prime}$ & 0,25 & 1 & 0,8 & 4 \\
\hline $15^{\prime \prime}$ & $2^{\prime}$ & 0,125 & 1 & 0,88 & 8 \\
\hline $7,5^{\prime \prime}$ & $2^{\prime}$ & 0,0625 & 1 & $\approx 1$ & 16 \\
\hline $1^{\prime}$ & $3^{\prime}$ & 0,33 & 1 & 0,75 & 3 \\
\hline $30^{\prime \prime}$ & $3^{\prime}$ & 0,17 & 1 & 0,85 & 6 \\
\hline $15^{\prime \prime}$ & $3^{\prime}$ & 0,08 & 1 & 0,9 & 12 \\
\hline $7,5^{\prime \prime}$ & $3^{\prime}$ & 0,04 & 1 & $\approx 1$ & 24 \\
\hline
\end{tabular}

Veliki broj proračuna prema opisanom matematičkom modelu daje pozitivne i realne rezultate. U konkretnoj situaciji potrebno je napraviti grafikone i analizu raspoloživih PT sredstava.

\section{Zaključak}

Dokazano je da kvantitativne analize omogućavaju validniju procenu situa- cije protivnika i vlastitih snaga u koncipiranju POB-a. Rezultate kvantitativnih analiza treba upoređivati sa statističkim rezultatima bojnih PT gađanja, taktičkih vežbi oklopnih i protivoklopnih jedinica. Bliskost rezultata pokazaće koje su analize realne, a koje to nisu.

Pri modelovanju i analizi POB-a ključni problem predstavlja pronalaženje optimalne vrednosti parametra $\rho$, jer ako je parametar realno definisan, celokupna analiza POB-a daće realne rezultate.

U članku je prezentovan samo deo mogućih analiza, a i pristupi ovoj problematici mogu biti različiti, dok rezultati iz prakse treba da ukažu na dalja moguća modelovanja protivoklopne borbe. Iznetu metodologiju procene mogu da koriste PT jedinice, ali i tenkovske (oklopne) jedinice u planiranju 
borbenih dejstava. Međutim, mogućnosti borbenih sredstava za POB iz vazdušnog prostora ovde nisu razmatrane. Pored aviona i helikoptera specijalno opremljenih za dejstvo po oklopnim ciljevima, razvoj planirajućih, nepogonjenih i pogonjenih kontejnera za rasejavanje potkalibarne municije i pojava rasipavajućih (klaster) bombi za dejstva po grupi tenkova i sl., zahteva posebnu analizu tenkovskih jedinica u proceni borbenih dejstava.

Literatura:

[1] Šepec, V. V.: Procena efikasnosti sistema veza u borbi, privatno izdanje, Beograd, 2004.

[2] Vojni leksikon, VIZ, Beograd, 1981.

[3] Matlab, User Guide, The Math Works Inc., Massachutecs, 1996. 


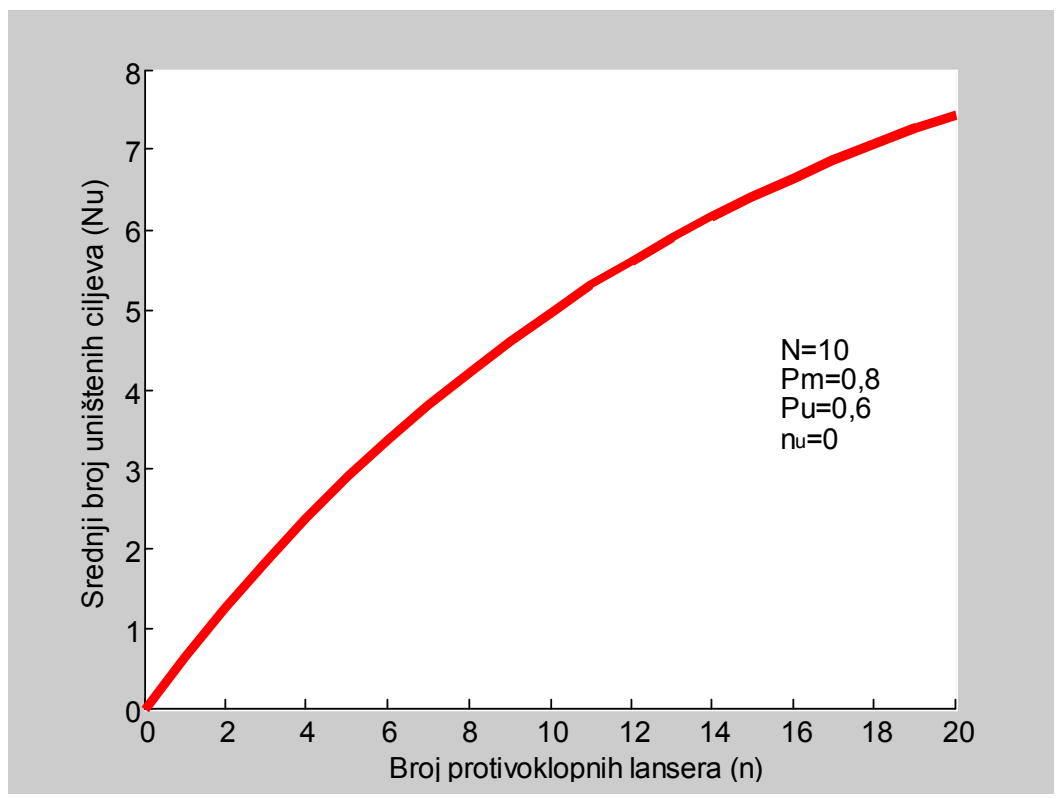

Sl. 1 - Zavisnost broja uništenih ciljeva od broja PO lansera 


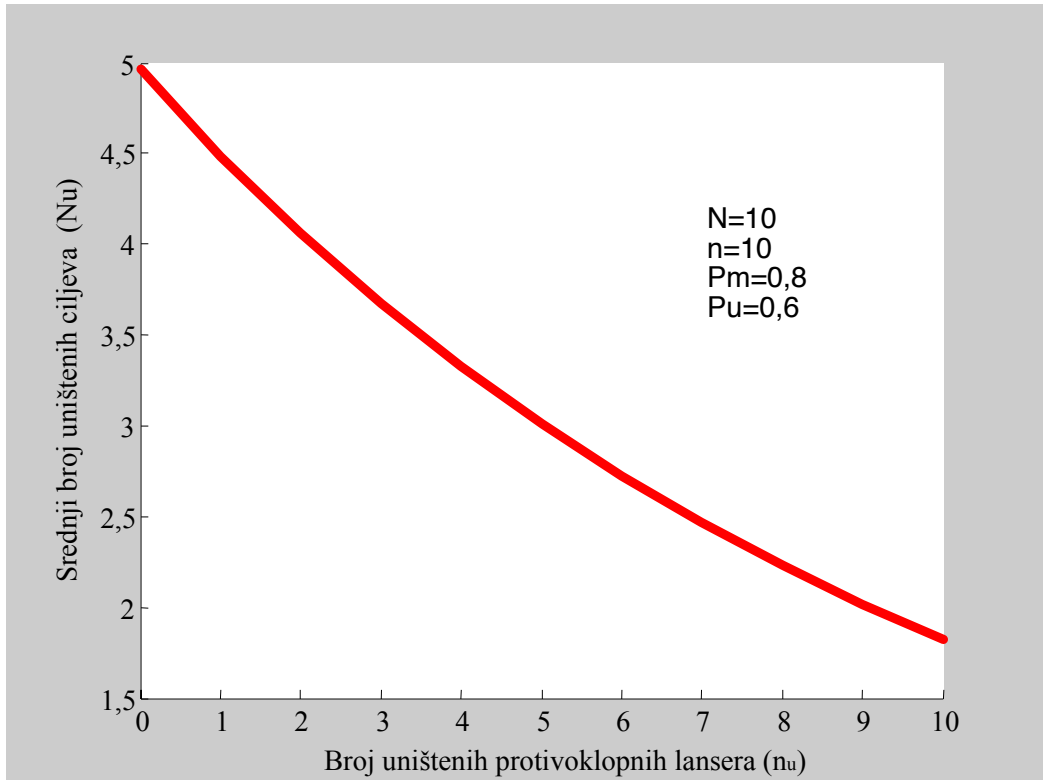

Sl. 2 - Zavisnost broja uništenih ciljeva od broja uništenih PO lansera

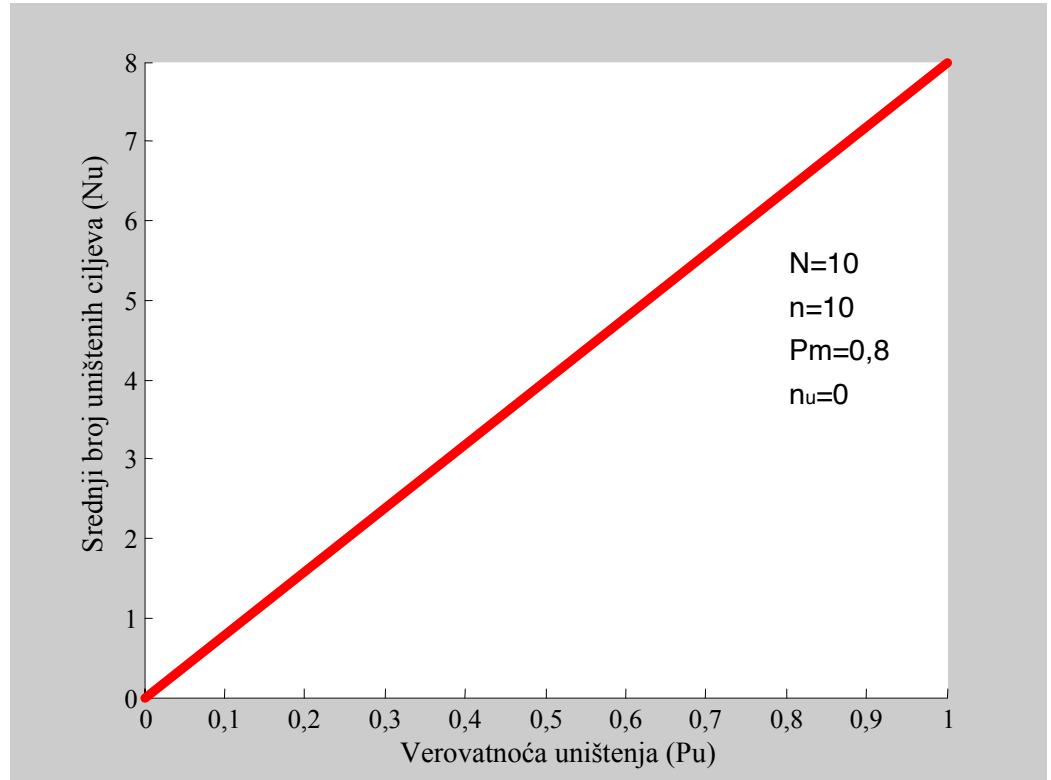

Sl. 3 - Zavisnost broja uništenih ciljeva od verovatnoće uništenja 


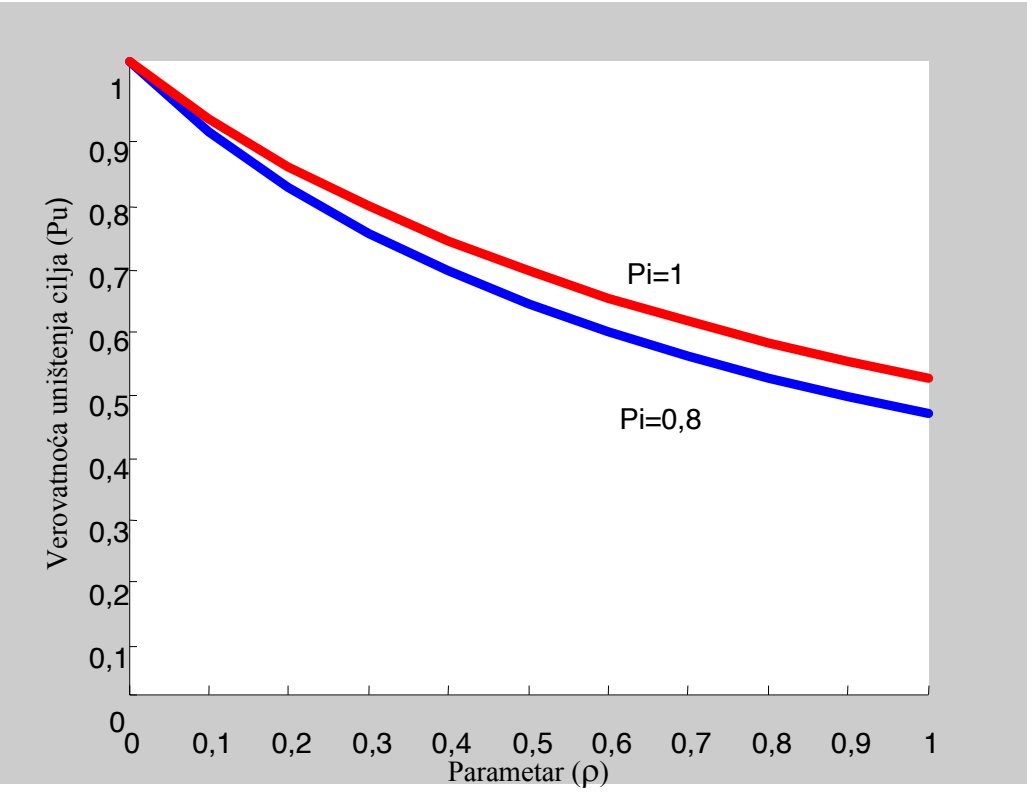

Sl. 4 -Zavisnost verovatnoće uništenja cilja od parametra $\rho$ 